\title{
Levator Ani/Bulbospongiosus
}

National Cancer Institute

\section{Source}

National Cancer Institute. Levator Ani/Bulbospongiosus. NCI Thesaurus. Code C112430.

A laboratory specimen consisting of the bulbocavernosus and the levator ani. 